\title{
Washout of a yeast population during continuous treatment of salad-oil-manufacturing wastewater
}

\author{
Shaokui Zheng ${ }^{a, b, *}$, Min Yang ${ }^{a}$, Yun Hee Park ${ }^{b}$, Fang Liu ${ }^{\text {a }}$ \\ ${ }^{a}$ State Key Laboratory of Environmental Aquatic Chemistry, Research Center for Eco-Environmental Sciences, Chinese Academy of Sciences, \\ P.O. Box 2871, Beijing 100085, China \\ ${ }^{\mathrm{b}}$ Department of Molecular Science and Technology, Ajou University, San 5, Woncheon-dong, Suwon 442-749, Republic of Korea \\ Received 6 March 2002; received in revised form 6 June 2002; accepted 18 July 2002
}

\begin{abstract}
During continuous treatment of salad-oil-manufacturing wastewater using yeast isolates, a large loss of biomass was observed, which subsequently reduced the treatment efficiency. The correlation between biomass washout and loss of species was monitored using the microbiological characteristics of the effluent and the aeration tank. Of the five yeast species, only Candida tropicalis ultimately remained in the aeration tank possibly because it had the best settleability. Addition of nitrogen to the final effluent stimulated the activity of this yeast, which resulted in a treatment efficiency similar to that of the mixed yeast system.
\end{abstract}

(C) 2002 Elsevier Science Ltd. All rights reserved.

Keywords: Yeast; Oil-rich wastewater; Continuous running; Biomass; Washout

\section{Introduction}

Recently, several reports have demonstrated the efficient treatment of high-strength organic wastewaters using yeast in open continuous treatment system (Chigusa et al., 1996; Zheng et al., 2001, 2002). However, few studies have investigated the development of isolates in a reactor, the effect of biomass washout on degradation efficiency, or strategies to restore degradation profiles in detail during the transformation from batch enrichment culture to continuous running. Therefore, using five yeast species obtained from previous studies (Zheng et al., 2001, 2002), we investigated the effect of population washout on the running performance during the treatment of salad-oil-manufacturing wastewater (SOMW).

\footnotetext{
Corresponding author. Address: State Key Laboratory of Environmental Aquatic Chemistry, Research Center for Eco-Environmental Sciences, Chinese Academy of Sciences, P.O. Box 2871, Beijing 100085, China. Tel.: +82-331-219-2458; fax: +82-331-216-8777.

E-mail address: zshaokui@yahoo.com.cn (S. Zheng).
}

\section{Methods}

\subsection{Yeast strains and wastewater}

The five yeast species, Rhodotorula rubra, Candida tropicalis, Candida utilis, Candida boidinii and Trichosporon cutaneum, and wastewater used in this study were described in previous studies (Zheng et al., 2001). The wastewater analyses followed standard methods (Committee of SEPA, 1998).

\subsection{Continuous operation in a bench-scale system}

The continuous treatment system used in this study was similar to that used for the classic conventional activated sludge process. The seed sludge preparation and the startup of the continuous system were reported in previous studies (Zheng et al., 2001). Diluted SOMW, containing approximately $1400-2200 \mathrm{mg} \mathrm{l}^{-1}$ of oil and $4100-7400 \mathrm{mg}^{-1} \mathrm{COD}$, was continuously fed into the system. The recycle rate was arbitrarily adjusted to ensure that the settled sludge could be returned effectively. The yeast cultures in the aeration tank sampled on day 10 were cultured for 2 days in batch mode, and the cells were collected and introduced into the aeration tank on day 12 . 


\subsection{Characteristics of yeast species}

Each yeast strain cultured for 3 days at $25^{\circ} \mathrm{C}$ (Zheng et al., 2002) was inoculated into 10-fold diluted SOMW in batch tests. At two-day intervals, cells were collected by centrifugation and added to the next batch of freshly diluted wastewater. The maximum specific growth rate of each yeast species was determined during the first two cycles. In the third cycle, the settling and oil removal rates of each species were examined. The settling fraction $x(-)$ was calculated using:

$x=\left(1-C_{\mathrm{s}} / C_{\mathrm{t}}\right) 100$

where, $C_{\mathrm{s}}\left(\mathrm{mg}^{-1}\right)$ is the supernatant MLSS value after settling for $30 \mathrm{~min}$ and $C_{\mathrm{t}}\left(\mathrm{mg}^{-1}\right)$ is the total MLSS value.

\subsection{Retreating effluents after population washout}

The final effluent was retreated in batch mode with (a) mixed cultures of five yeast species ('mixed yeast cultures'), (b) cells left in the aeration tank at the end of continuous run with the addition of $500 \mathrm{mgl}^{-1}$ total ammonia ('nitrogen addition'), and (c) cells left in the aeration tank at the end of continuous run without added ammonia, as a control.

\section{Results and discussion}

Initially, high-strength influent, designed to give a load of 1.5-2.5 $\mathrm{kgCOD} \mathrm{kg}^{-1} \mathrm{MLSS} \mathrm{d}^{-1}$ according to Chigusa et al. (1996), was introduced into the continuous system. Owing to the rapid decrease in MLSS concentration in the aeration tank and the high MLSS level in the effluent, the initial loading was increased to 5 $\mathrm{kgCOD} \mathrm{kg}^{-1} \mathrm{MLSS} \mathrm{d}^{-1}$ (Fig. 1). Three yeast species, $T$. cutaneum, $C$. tropicalis, $C$. boidinii, were found in the effluent on day 10 , with one third as many viable cells as in the aeration tank.

Although fresh yeast cells from batch cultures were added to the aeration tank on day 12, the biomass washout continued until the MLSS levels in the effluent were reduced to a minimum of below $100 \mathrm{mg} \mathrm{l}^{-1}$ (Fig. 1). At that time, only $C$. tropicalis was detected in the aeration tank.

Of the five yeast species, $C$. utilis and $C$. boidinii had the greatest degradation capability, $C$. tropicalis settled the most effectively, and $R$. rubra and $C$. utilis had the highest specific growth rates, approximately double those of the other strains (Table 1). Obviously, settleability was the most important factor in the treatment system; since $C$. tropicalis, which had the best settleability, was the only remaining yeast in the aeration tank at the end of the run.

Although the influent dilution rate $(0.1-0.11)$ and the total dilution rate including the influent and return flow

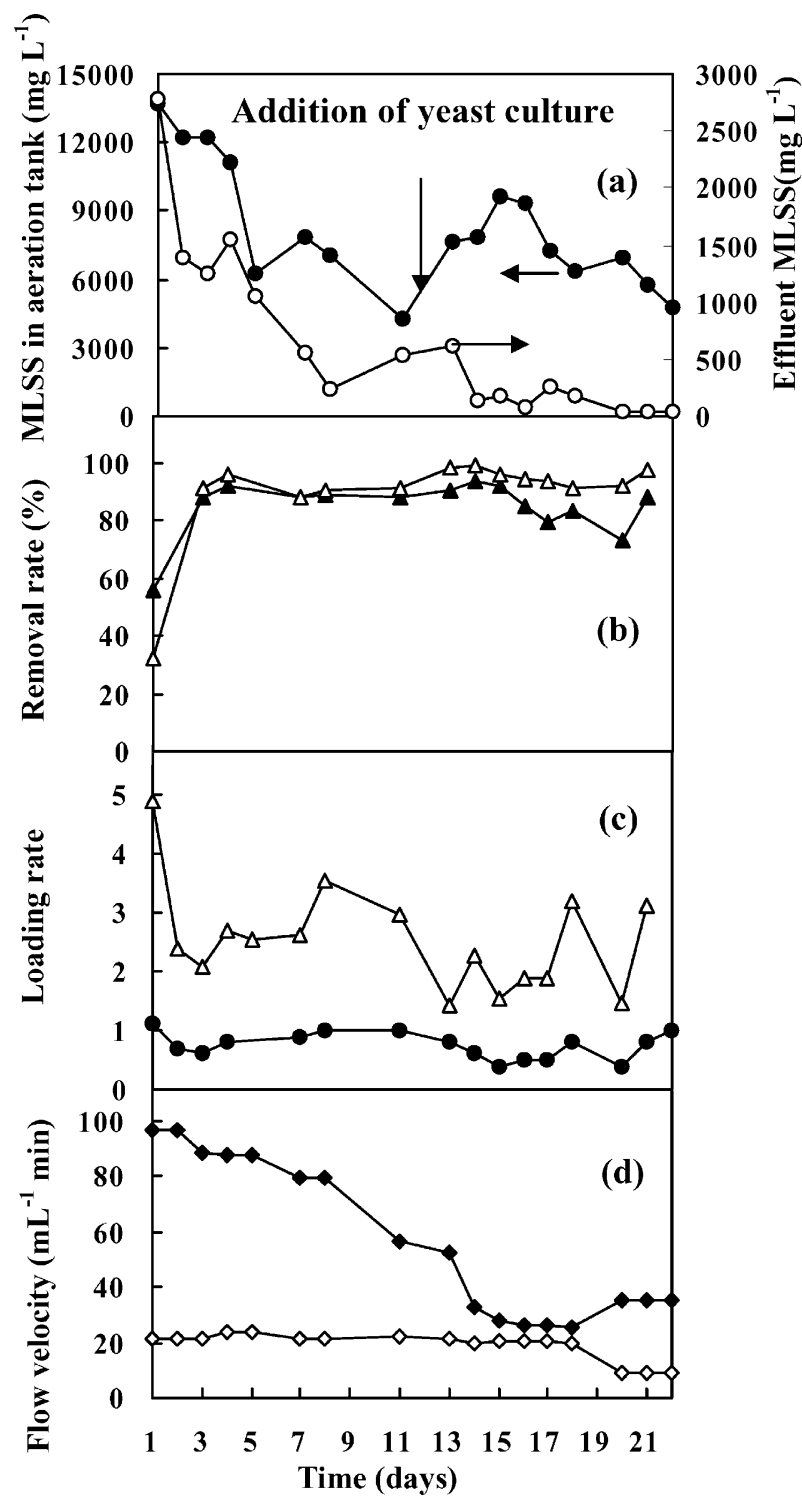

Fig. 1. Change in parameters during the continuous treatment of SOMW during 22 days: (a) $\bullet$ : MLSS in aeration tank, $\bigcirc$ : effluent MLSS ( $\mathrm{mg} \mathrm{l}^{-1}$ ); (b) $\Delta$ : COD removal rate, $\triangle$ : oil removal rate (\%); (c) $\triangle$ : COD loading rate $\left(\mathrm{kgCOD} \mathrm{kg}^{-1} \mathrm{MLSS} \mathrm{d}^{-1}\right)$, $\bullet$ : oil loading rate $\left(\mathrm{kg} \mathrm{oil} \mathrm{kg}^{-1} \mathrm{MLSS} \mathrm{d}^{-1}\right)$; (d) $\diamond$ : influent flow velocity, $\diamond$ : return flow velocity $\left(\mathrm{ml} \mathrm{min}^{-1}\right)$. $\downarrow$ : addition of yeast culture.

(0.22-0.59) resulted in a suitable influent COD load, most of the biomass was washed out of the aeration tank. Only cells that settled to the bottom of the sedimentation column were returned to the aeration tank. Biomass washout often plays different roles during the transformation from batch culture to a continuous one (Chigusa et al., 1996; Klecka and Maier, 1985). In this study, this loss of species might have affected the treatment efficiency of oil and COD toward the end of run.

The effects of mixed yeast culture and nitrogen addition on retreating the effluent were compared in batch mode. The addition of nitrogen obviously stimulated the growth of yeast resulting in treatment efficiency similar to 
Table 1

The oil removal rate, settling fraction, and specific growth rates of five yeast species in 10 -fold diluted SOMW at $25{ }^{\circ} \mathrm{C}$

\begin{tabular}{llllll}
\hline Species & R. rubra & C. tropicalis & C. utilis & C. boidinii & T. cutaneum \\
\hline $\begin{array}{l}\text { Oil removal rate } \\
\left(\mathrm{kg} \mathrm{oil} \mathrm{kg}^{-1} \text { MLSS d }\right.\end{array}$ & 0.64 & 0.71 & 0.96 & 0.94 & 0.62 \\
$\begin{array}{l}\text { Settling fraction (\%) } \\
\mu_{\max }\left(\mathrm{h}^{-1}\right)\end{array}$ & 0 & 76 & 0 & 44 & 49 \\
\hline
\end{tabular}

Table 2

Comparison of the effects of mixed yeast culture treatment and the addition of nitrogen for retreating effluent ${ }^{\mathrm{a}}$

\begin{tabular}{|c|c|c|c|c|c|c|c|c|}
\hline \multirow[t]{2}{*}{ Treatments } & \multicolumn{2}{|l|}{ MLSS } & \multicolumn{2}{|c|}{ Final value $\left(\mathrm{mg} \mathrm{l}^{-1}\right)$} & \multicolumn{2}{|c|}{ Removal (\%) } & \multicolumn{2}{|c|}{ Removal speed $^{\mathrm{b}}$} \\
\hline & Initial & Final & Oil & COD & Oil & COD & Oil & COD \\
\hline Mixed yeast cultures & $313 \pm 15$ & $903 \pm 40$ & $72 \pm 3$ & $999 \pm 45$ & 85 & 68 & 0.70 & 3.52 \\
\hline Nitrogen addition & $250 \pm 10$ & $1237 \pm 100$ & $78 \pm 4$ & $915 \pm 45$ & 84 & 71 & 0.56 & 2.99 \\
\hline Control & $227 \pm 13$ & $227 \pm 9$ & $318 \pm 12$ & $3071 \pm 135$ & 36 & 2 & 0.78 & 0.29 \\
\hline
\end{tabular}

${ }^{\text {a }}$ Values are the means \pm standard errors of three determinations.

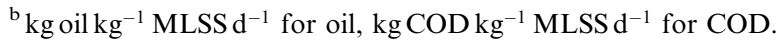

that of the mixed yeast system (Table 2). The final MLSS values were about three times higher than the initial one with mixed culture addition, and five times higher with nitrogen addition. Compared to other wastewater from an oil-processing factory (Chigusa et al., 1996), SOMW in this study had a far higher ratio of COD to nitrogen. Therefore, ammonia should be added to counteract the reduction in performance due to the loss of species.

\section{Acknowledgement}

Thanks were given to NSFC (National Science Foundation of China) for their support (no. 50078053).

\section{References}

Chigusa, K., Hasegawa, T., Yamamoto, N., Watanabe, Y., 1996. Treatment of wastewater from oil manufacturing plant by yeasts. Water Sci. Technol. 34, 51-58.

Committee of State Environmental Protection Agency, 1998. Water and Wastewater Monitoring and Analysis, third ed. China Construction Industry Press, China (in Chinese).

Klecka, G.M., Maier, W.J., 1985. Kinetics of microbial growth on pentachlorophenol. Appl. Environ. Microbiol. 49, 46-53.

Zheng, S., Yang, M., Lv, W., Liu, F., 2001. Study on sludge expansion during the treatment of salad oil manufacturing wastewater by yeasts. Environ. Technol. 22, 533-542.

Zheng, S., Yang, M., Li, P., 2002. Seed yeast cultivation for salad oil manufacturing wastewater treatment. J. Environ. Sci. 14, 3943. 